\title{
Beta Risk and Regime Shift in Market Volatility
}

\author{
Roland Shami $^{*}$ and Don U.A. Galagedera \\ Department of Econometrics and Business Statistics \\ Monash University
}

\begin{abstract}
In this paper, we relate security returns in the thirty securities in the Dow Jones index to regime shifts in the market portfolio (S\&P500) volatility. We model market volatility as a multiple-state Markov switching process of order one and estimate non-diversifiable security risk (beta) in the different market volatility regimes. We test the significance of the premium of the beta risk associated with the different market regimes and find evidence of a relationship between security return and beta risk when conditional on the up and down market movement.
\end{abstract}

Key words: Markov regime-switching, market volatility, beta risk.

JEL Classification: G12, G15

\section{Introduction}

When testing the validity of asset pricing models, especially the capital asset pricing model $\left(\mathrm{CAPM}^{1}\right)$, many studies examine models conditional on market movements. A common method to capture market movements is to define up and down markets based on some arbitrarily chosen

Correspondence to: Roland Shami, Department of Econometrics and Business Statistics, Monash University, PO Box 197, Caulfield East, Victoria 3145, Australia. email: Roland.Shami@buseco.monash.edu.au

${ }^{1}$ CAPM conveys the notion that securities are priced so that their expected return will compensate investors for their expected risk. Symbolically, CAPM is expressed as $\left.E\left(R_{i}\right)=R_{f}+\beta_{i} \mid E\left(R_{m}\right)-R_{f}\right\rfloor$ where, $R_{i}$ is the return on security $i, R_{f}$ is the return on risk-free asset, $R_{m}$ is the return on the market portfolio and $\beta_{i}$ is the measure of security $i$ 's non-diversifiable risk relative to that of the market portfolio. 
threshold value. For example, Kim and Zumwalt (1979) used three threshold levels, namely, average monthly market return, average risk-free rate and zero. Several studies have investigated the risk-return relationship in the tails of the market return distribution. For example, Crombez and Vander Vennet (2000) defined three regimes for market movements, namely, substantially upward moving, neutral, and substantial bear. They used the following threshold points: (i) the average positive market return and average negative market return, (ii) the average positive market return plus half the standard deviation of positive market returns and average negative market return less half the standard deviation of negative market returns, and (iii) the average positive market return plus three-quarters of the standard deviation of positive market returns and average negative market return less three-quarters of the standard deviation of negative market returns. Crombez and Vander Vennet (2000) assessed the robustness of the regime classification on the conditional beta risk-return relationship by varying the width of the neutral interval. They found the relationship to be stronger as the classification of up and down markets became more pronounced.

An alternative approach to capture market movements is through market volatility regimes. Since the introduction of ARCH/GARCH-type processes by Engle (1982) and others, testing for, and modelling of, time-varying volatility (variance/covariance) of stock market returns (and hence the time-varying beta) have been given considerable attention in the literature. See Bollerslev, Engle and Wooldridge (1988) - the first study to model the beta in terms of timevarying variance/covariance - and the survey paper by Bollerslev, Engle and Nelson (1994). The ARCH-based empirical models appear to provide stronger evidence, though not convincingly, of the risk-return relationship than do the unconditional models. For example, Fraser, Hamelink, Hoesli and MacGregor (2000) compared the cross-sectional risk-return relationship obtained with an unconditional specification of the asset's betas with betas obtained through Quantitative 
Threshold ARCH (QTARCH ${ }^{2}$ ) and GARCH-M ${ }^{3}$ models. In all specifications, they allowed for possible negative return-risk relationships when excess return on the market is negative. They observed that the QTARCH specification, in which they allowed for asymmetries in the first and second moments of returns, yields a significant beta without having to account for up and down markets. Recently, Galagedera and Faff (2003) incorporated market movements into the asset pricing model by partitioning the market returns into three regimes corresponding to the size of the conditional market volatility modelled via an ARCH/GARCH-type proces. They reported that the beta risk premium in the three market volatility regimes is priced only in the pricing model conditional on the sign of realised market return.

The objective of this paper is to investigate whether securities' responses to the market vary, depending on changing market volatility as defined by a Markov switching process. In particular, we aim to investigate whether market risk as measured by beta estimated across different market volatility regimes are useful in explaining asset/portfolio returns. Postulating distinct betas across different market volatility regimes, a multiple-state Markov regime-switching threshold model, with defined levels of probabilities of being in each state as threshold parameters, will be employed to examine the above issues.

The paper is organised as follows: The volatility switching models are specified in Section 2. In Section 3, we define a multi-beta asset pricing model. The data series used in this study are described in Section 4. Section 5 is devoted to the empirical results and their analysis. This is followed by a concluding section.

\footnotetext{
2 See Gourieroux and Monfort (1992) for details.

${ }^{3}$ Due to Bollerslev, Engle and Wooldridge (1988).
} 


\section{Volatility-switching model specification}

The return generating process of the market portfolio is postulated as:

$$
\text { Model } \mathrm{A}_{l}: r_{m t}=\mu+\left(\sum_{i=1}^{l} \sigma_{i} S_{i t}\right) \varepsilon_{t}
$$

where $r_{m t}$ is return of the market portfolio in excess of the risk-free rate, $\mu=E\left(r_{m t}\right), l$ is the number of regimes $(l \geq 2), S_{i t}$ is an unobserved binary variable that identifies which one of the $l$ regimes the market is in at time $t$ ( $S_{i t}=1$ if the market is in the volatility regime $i$ and $S_{i t}=0$ otherwise), and $\varepsilon_{t} \mid \Phi_{t-1} \sim N(0,1)$ where $\Phi_{t-1}$ is information set at time $t-1$. In Model A, we assume that the changes in regimes can only affect the volatility of the market return distribution and there is no switching in mean ${ }^{4}$. In other words, we assume that market returns are drawn from $l$ distributions that differ only in their variances. The volatility regimes are characterised by $\sigma_{1}$, $\sigma_{2}, \ldots, \sigma_{l}$ where $\sigma_{1}<\sigma_{2}<\ldots<\sigma_{l}$. It is assumed further that $S_{i t}$ follows a Markov chain of order one with constant transition probabilities where

$$
\begin{aligned}
& P\left(S_{j, t+1}=1 \mid S_{i t}=1\right)=p_{i j}, \\
& 0 \leq p_{i j} \leq 1 \quad \forall i, j \\
& \sum_{j=1}^{l} p_{i j}=1 \quad \forall i
\end{aligned}
$$

and

When there is no switching in market volatility, $l=1$ and Model A reduces to the single regime model given as

$$
r_{m t}=\mu+\sigma \varepsilon_{t}
$$

\footnotetext{
${ }^{4}$ Studies have shown that the switching behaviour in market portfolio returns can be primarily attributed to the switching in volatility (Assoe, 1998; Hess, 2003).
} 


\section{Estimation}

Let $y_{t}$ denote the observed return at time $t$ whose distribution is denoted as $f$, and let $\Phi_{t}$ denote the information set at time $t$ where $\Phi_{t}=\left(y_{1}, y_{2}, \ldots . y_{t}\right)$. The distribution from which returns are drawn is determined by the state variable $S_{i t}$. Following Hamilton's (1989) procedure for filtering, the iterative algorithm uses an input value at time $t, P\left(S_{t} \mid \Phi_{t}\right)$, which will be developed by using Bayes theorem into the output value at time $t+1, P\left(S_{t+1} \mid \Phi_{t+1}\right)$. Note here that $P\left(S_{t} \mid \Phi_{t}\right)$ is a vector of $l$ elements representing the probabilities of being in the $l$ different states and that the sum of all elements is equal to 1 . To set up the iteration, the procedure needs an initial value $P\left(S_{1} \mid \Phi_{1}\right)$. This value is set equal to the unconditional probability $P\left(S_{1}\right)$ that has $l$ elements given by the solution of the following equation

$$
\tau_{\pi_{0}}=\pi_{0}
$$

where $\pi_{0}$ represents the limiting probability of the Markov process and $\tau$ is the transition matrix between the different states given by

$$
\tau=\left[\begin{array}{lll}
p_{11} & p_{12} & \\
p_{21} & & p_{1 l} \\
& & \\
p_{l 1} & & p_{l l}
\end{array}\right] .
$$

The following iterative steps will be carried out.

Input: $P\left(S_{t} \mid \Phi_{t}\right)$.

Step-I: $P\left(S_{t+1}, S_{t} \mid \Phi_{t}\right)=P\left(S_{t+1} \mid S_{t}\right) P\left(S_{t} \mid \Phi_{t}\right)$.

Step-II: $P\left(S_{t+1} \mid \Phi_{t}\right)=\sum_{S_{t}} P\left(S_{t+1}, S_{t} \mid \Phi_{t}\right)$.

Step-III: $f\left(y_{t+1}, S_{t+1} \mid \Phi_{t}\right)=f\left(y_{t+1} \mid S_{t+1}, \Phi_{t}\right) P\left(S_{t+1} \mid \Phi_{t}\right)$, 
where $f\left(y_{t+1} \mid S_{j, t+1}, \Phi_{t}\right)=\frac{1}{\sqrt{2 \pi \sigma_{j}^{2}}} e^{-\frac{\hat{e}_{t+1}^{2}}{2 \sigma_{j}^{2}}}, \sigma_{j}$ is the standard deviation of error when in state $j$ and $\hat{e}$ is the estimated error of the model being estimated.

Step-IV: $f\left(y_{t+1} \mid \Phi_{t}\right)=\sum_{S_{t+1}} f\left(y_{t+1}, S_{t+1} \mid \Phi_{t}\right)$

Step-V (output): $P\left(S_{t+1} \mid \Phi_{t+1}\right)=\frac{f\left(y_{t+1}, S_{t+1} \mid \Phi_{t}\right)}{f\left(y_{t+1} \mid \Phi_{t}\right)}$

We should note here that Step-IV provides the conditional distributions for the calculation of the likelihood function $L=\prod_{t=1}^{T} f\left(y_{t+1} \mid \Phi_{t}\right)$ where $T$ is the sample size.

\section{Development of the asset pricing model}

In the following sub-section, we describe how each sampled day is classified into only one of the market volatility regimes. An unconditional multiple-beta security return-generating process is defined next.

\subsection{Market regimes}

First, we select a Markov regime-switching volatility model (Model A) for daily market returns and obtain the estimates for probabilities that a given day belongs in the various volatility regimes. Then, based on the magnitude of these probability estimates we assign each day to one of the market volatility regimes, using an indicator function. Specifically, day $t$ is assigned to regime $j$ if regime $j$ has the highest probability of occurrence among all $l$ regimes.

Define a dummy variable $d_{j t}$ as:

$$
d_{j t}=\left\{\begin{array}{ll}
1 & \text { if } P\left(S_{j t}=1\right)>P\left(S_{k t}=1\right) \text { for all } j \neq k \\
0 & \text { otherwise }
\end{array},\right.
$$


where $j=1,2, \ldots, l$ and $k=1,2 \ldots, l$. Now define $D_{t}=\left[d_{1 t}, d_{2 t} \ldots, d_{l t}\right]^{\prime}$ a column vector made up of the dummy variables that corresponds to the $l$ regimes. $D_{t}$ is then used to classify each day in the sample period into one of the $l$ different market volatility regimes. For example, for $l=3$, three market volatility regimes may be defined: low volatility market, neutral volatility market and high volatility market.

\subsection{A multiple-beta security return-generating process}

In empirical investigation of the single-beta CAPM, the beta is estimated using the market model given as:

$$
\text { Model B: } R_{i t}=\alpha_{i}+\beta_{i} R_{m t}+\varepsilon_{i t}
$$

where, $\varepsilon_{i t} \sim N\left(0, \sigma^{2}\right)$. We refer to Model $\mathrm{B}$ as the unconditional single-beta security returngenerating process. To estimate the betas in the $l$ volatility market regimes, we extend the market model given in (9) as:

$$
\text { Model C: } R_{i t}=\alpha_{i}+\beta_{i}^{\prime} D_{t}^{\prime} R_{m t}+\varepsilon_{i t}
$$

where, $\beta_{i}=\left[\beta_{i 1}, \beta_{i 2}, \ldots, \beta_{i l}\right]^{\prime}$ and $\varepsilon_{i t} \sim N\left(0, \sigma^{2}\right)$. We refer to Model $\mathrm{C}$ as the unconditional $l$-beta security return-generating process.

\section{Data}

We use the daily price series of the thirty securities in the Dow Jones Industrial index. The data covers the period from 2 January 1990 to 23 May 1996, and consists of 1619 observations for each security. The daily returns are calculated as the change in the logarithm of the closing prices of successive days. The return on the Standard and Poor's 500 Index (S\&P500) is used to proxy the market portfolio return and the return on the US 1-month Treasury Bill (TB) is used to proxy the risk-free return. 
Table 1 provides some summary statistics of the thirty securities, the US 1-month TB and the market portfolio returns. The returns vary widely across the securities, with the highest being 13.26 per cent and the lowest being -26.15 per cent. The market return, as expected, has a smaller range with the lowest and the highest returns being -3.73 per cent and 3.66 per cent respectively. The standard deviation of the market return distribution, 0.73 per cent, is much smaller compared to that of the securities, of which the lowest is 1.13 per cent and the highest is 2.36 per cent. The market and seven securities are negatively skewed. The excess kurtosis of one security, PM, is extremely high compared to the others. When PM is left out the excess kurtosis varies only between 6.40 and 0.96 . The excess kurtosis of the market return distribution is 2.39. The US 1month TB returns distribution is tri modal, positively skewed and has mean 0.0128 per cent and standard deviation 0.0039 per cent.

\section{Results and Discussion}

\subsection{Market volatility model}

We apply model (1) for $l=2$ to 6 such that five different switching models with volatility switching states ranging from 2 to 6 are estimated. The number of parameters in each model increases with the increase in the number of states. If $l$ is the number of states, then the parameters of the model consists of the mean $\mu, l(l-1)$ probabilities and $l$ standard deviations for a total of $l^{2}+1$ coefficients to estimate. We select the best model using the AIC which imposes a penalty for additional coefficients. AIC is given by

$$
A I C=-2 l i k / T+2 k / T,
$$

where lik is the log likelihood value and $k$ is the number of parameters in the model. The models are estimated with daily data spanning 1366 days and ranging from January 1990 to May 1995. We left the remaining 252 days for testing purposes. The estimation results reported in Table 2 
reveals that the model with the least AIC is the one with three volatility regimes. Hence the asset pricing model that we consider for further investigation is assumed to be

$$
E\left(R_{i}\right)=R_{f}+\lambda_{L} \beta_{i L}+\lambda_{N} \beta_{i N}+\lambda_{H} \beta_{i H}
$$

where, $\beta_{i L}, \beta_{i N}$ and $\beta_{i H}$ are the beta risk associated with the low, neutral and high market volatility regimes.

\subsection{Analysis of the risk-return relationship}

As indicated earlier, the analysis of the risk-return relationship is based on a two-stage procedure. In the first stage of the analysis, the systematic risks, $\beta_{i L}, \beta_{i N}$ and $\beta_{i H}$, are estimated. In the second stage we test whether the systematic risks are priced or not.

\section{Estimating beta risks}

We estimated Model $C$ with $l=3$ for each security in the sample using time series data through a period of 1366 days. In addition, we estimated the constant beta in the market model given in (9). The results are reported in Table 3. The results reveal that the beta in the low volatility market is significantly different from zero only in twelve of the thirty securities where as in the neutral and high volatility regimes the beta is significant at the one percent level in all securities. The constant beta is also significant at the one percent level and this was observed in all securities.

We also tested whether or not the betas estimated in the low, neutral and high volatility regimes are equal for each of the thirty securities. Table 4 reports the results in the $F$-test of $H_{0}: \beta_{i L}=\beta_{i N}, H_{0}: \beta_{i L}=\beta_{i H}$ and $H_{0}: \beta_{i N}=\beta_{i H}$ against the alternative of not equal and of $H_{0}: \beta_{i L}=\beta_{i N}=\beta_{i H}$ against the alternative of at least one is different from the others. In four securities namely, Alcoa, ATT, Coca Cola and Home Depot there is statistical evidence that beta 
in the low volatility regime is different from the beta in the neutral volatility regime. A similar observation is made for the same set of securities for beta in the low and high volatility regimes as well. On the other hand, significantly different beta in the neutral and high volatility regimes are observed only in the securities Boeing, Amex, CITIGRP and Kodak, Wal-Mart and Intel.

\section{Estimating beta risk premiums}

Having found evidence that beta is significantly different from zero in the low, neutral and high volatility markets, we extended our investigation to test whether or not the beta risks in these markets are priced and the risk premiums are equal or not. In the sample period immediately following the estimation period (252 days), using cross-sectional data we test whether the systematic risks are priced or not. Here, we consider the betas estimated in the first stage as proxies for the true betas in the 252-day period immediately following the beta estimation period. To ascertain whether beta in the three regimes is priced, the cross-sectional regression model

$$
\text { Model D: } R_{i t}=\lambda_{0}+\lambda_{L} \beta_{i L}+\lambda_{N} \beta_{i N}+\lambda_{H} \beta_{i H}+\varepsilon_{i t}
$$

where $\varepsilon_{i t} \sim N\left(0, \sigma^{2}\right)$ is estimated 252 estimates for each beta risk premium, $\lambda_{L}, \lambda_{U}$ and $\lambda_{H}$ were obtained.

Table 5 reports the summary statistics of the estimated premiums together with the results of testing $H_{0}: \bar{\lambda}_{i}=0$ against $H_{1}: \bar{\lambda}_{i} \neq 0$ for $i=L, U, H$. The results reveal that none of the betas is priced at the ten percent significance level. However, the average premium in all three market volatility regimes has the expected sign. We believe that the lack of evidence in beta risk pricing might be due to the bias that creeps in as a result of using realized return in equation (13) instead of the expected as derived in (12). Therefore, following Pettengill, Sundaram and Mathur (1995), 
to ascertain whether beta in the three volatility regimes is priced or not, the cross-sectional regression model given by

$$
\begin{gathered}
R_{i t}=\lambda_{0}+\lambda_{L}^{U} \delta \beta_{i L}+\lambda_{L}^{D}(1-\delta) \beta_{i L}+\lambda_{N}^{U} \delta \beta_{i N}+\lambda_{N}^{D}(1-\delta) \beta_{i N} \\
+\lambda_{H}^{U} \delta \beta_{i H}+\lambda_{H}^{D}(1-\delta) \beta_{i H}+\varepsilon_{i t}
\end{gathered}
$$

where $\delta=1$ for up market, $\delta=0$ for down market and $\varepsilon_{i t} \sim N\left(0, \sigma_{i}^{2}\right)$ is estimated for each day in the testing period. We refer to (14) as the conditional three-beta risk-return relationship. Like Pettengill, Sundaram and Mathur (1995), we postulate that in the time periods where the market return in excess of the risk-free rate is negative it is reasonable to infer an inverse relationship between realized return and beta. Accordingly, we expect the beta risk premium in the up market to be positive and the beta risk premium in the down market to be negative. A positive and statistically significant beta risk premium in the up market and a negative and statistically significant beta risk premium in the down market is sufficient to suggest a systematic relationship between the beta in the low, neutral and high volatility regimes and the security returns.

We estimated equation (14), the conditional three-beta return generating process, in the 252 days in the testing period of which $110(43.7 \%)^{5}$ are 'up market' days and 142 are 'down market' days. An analysis of the results reported in Table 6 indicates that the risk premium is significantly different from zero and has the correct sign in the low and neutral market volatility regimes. In the high market volatility regime though the beta risk premium is not significantly different from zero has the expected sign. Therefore, in the dataset that we have considered, there is considerable evidence to suggest that the beta risk premium in the 'up market' is positive and the beta risk premium in the 'down market' is negative and this is true with the beta in the low, neutral and high market volatility regimes. The unconditional model failed to uncover a systematic relation

${ }^{5}$ Pettengill, Sundaram and Mathur (1995) using monthly US data from Jan 1926 through Dec 1990, reported $57.6 \%$ of the months correspond to 'up market' days. Faff (2001) study that used monthly Australian data over the period 1974 to 1995 reported that $54.2 \%$ of the months provide positive excess market returns. 
between the beta in the low, neutral and high volatility regimes and the security returns but the conditional model does.

\section{Conclusion}

In this paper, we examined the appropriateness of a conditional three-beta model as a security return-generating process. First, we modelled volatility of the market portfolio return generating process as a Markov regime switching process of order one. A sample of daily returns of the S\&P500 index that we use as a proxy for the market portfolio reveals that the model with three volatility regimes appears to model the market returns better compared to the competing models which included two, four, five and six volatility regimes. In the chosen model with three volatility regimes there is strong volatility switching behaviour with high-volatility regime being more persistent than the low-volatility regime.

We assigned each sampled day into one of the three volatility regimes based on the probability that a given day belongs in a volatility regime. Specifically, a given day is assigned to the regime with the highest probability of occurrence among all three regimes. A three-beta asset-pricing model is then specified and tested. The three betas correspond to the low, neutral and high market volatility regimes specified by the probability estimates.

An analysis of the returns in the securities in the Dow Jones index overwhelmingly suggests that the betas in the low, neutral and high volatility regimes are positive and significant. In most of the sectors the betas were not found to be significantly different in the three regimes. For some securities, the beta in the high volatility regime however is more likely to be different from the neutral volatility regime. 
We also investigated whether or not the betas are priced in the cross-sectional regression. We find that the beta risk premium in the low and neutral market volatility regimes is priced. These significant results are uncovered only in the pricing model conditional on the realised market return, while the unconditional model does not uncover such significant relationship. In the conditional three-beta asset-pricing model, the beta risk premiums are positive and significantly different from zero in the up market and are negative and significantly different from zero in the down market. That is, we have strong evidence to suggest that the components of the total portfolio return variations systematically related to the low and neutral market volatility regimes are priced.

\section{References}

Assoe, K.G. "Regime-switching in Emerging Stock Market Returns.” Multinational Finance Journal, 2 (1998), 101-132.

Bollerslev, T., Engle, R.F., and D. Nelson. “ARCH Models.” In Handbook of Econometrics, Volume IV, R.F. Engle and D.L. McFadden, eds. Amsterdam: North Holland (1994).

Bollerslev, T., Engle, R.F. and J. M. Wooldridge. "A Capital Asset Pricing Model with Time Varying Covariances.” Journal of Political Economy, 96 (1988), 116-131.

Crombez, J., and R. Vander Vennet. "Risk/Return Relationship Conditional on Market Movements on the Brussels Stock Exchange.” Tijdschrift voor Economie en Management, 45 (2000), 163-188.

Engle, R.F. “Autoregressive Cconditional Heteroscedasticity With Estimates of the Variance of U.K. Inflation.” Econometrica, 50 (1982), 122-150.

Faff, R. “A Multivariate Test of a Dual-Beta CAPM: Australian Evidence.” Financial Review, 36 (2001), 157-174.

Fraser, P., Hamelink, F., Hoesli, M. and MacGregor, B. "Time-varying betas and cross-sectional return-risk relation: evidence from the UK.” in Ecole des Hautes Etudes Commerciales, University of Geneva, Switzerland (2000).

Galagedera, D.U.A. and R. Faff. "Modelling the Risk and Return Relationship Conditional on Market Volatility." Proceedings of the $16^{\text {th }}$ Australasian Finance and Banking Conference, (2003), Sydney, Australia. 
Gourieroux, C. and a. Monfort. “Qualitative Threshold ARCH Models.” Journal of Econometrics, 52 (1992), 159-199.

Hess, M.K. "What Drives Markov Regime-Switching Behaviour of Stock Markets? The Swiss case. ”International Review of Financial Analysis, 153 (2003), (in press).

Kim, M.K., and J.K. Zumwalt. "An Analysis of Risk in Bull and Bear Markets.” Journal of Financial and Quantitative Analysis, 14 (1979), 1015-1025.

Pettengill, G.N., Sundaram, S., and L. Mathur. "The Conditional Relation Between Beta and Returns.” Journal of Financial and Quantitative Analysis, 30 (1995), 101-116. 
Table 1. Some descriptive statistics of the distributions of the continuously compounded daily returns of Dow Jones industrial securities

\begin{tabular}{lrrrrrr}
\hline Security & Mean & \multicolumn{1}{c}{ Max } & \multicolumn{1}{c}{ Min } & $\begin{array}{r}\text { Standard } \\
\text { deviation }\end{array}$ & Skewness & \multicolumn{1}{c}{$\begin{array}{c}\text { Excess } \\
\text { kurtosis }\end{array}$} \\
\hline Dupont & 0.0437 & 7.0351 & -6.1548 & 1.4405 & 0.1989 & 1.3886 \\
Boeing & 0.0474 & 8.0165 & -11.7571 & 1.6119 & -0.0468 & 3.9943 \\
Caterpillar & 0.0525 & 8.8147 & -10.8175 & 1.7651 & 0.0510 & 3.5391 \\
Alcoa & 0.0316 & 8.1309 & -8.3716 & 1.6607 & 0.2003 & 1.5540 \\
Amex & 0.0270 & 9.6100 & -9.7466 & 1.9364 & 0.1239 & 1.9854 \\
ATT & 0.0195 & 10.1103 & -6.4044 & 1.3310 & 0.3214 & 3.1347 \\
CITIGRP & 0.0914 & 11.2095 & -10.6916 & 2.0009 & 0.0083 & 2.3436 \\
Coca Cola & 0.0973 & 7.5945 & -5.7500 & 1.3933 & 0.1811 & 1.7486 \\
Home Depot & 0.1144 & 9.0151 & -10.3622 & 1.9034 & -0.0139 & 1.7856 \\
GE & 0.0597 & 5.9719 & -6.3084 & 1.2349 & 0.0270 & 1.7511 \\
GM & 0.0176 & 7.1153 & -8.3560 & 1.8797 & 0.0812 & 0.9682 \\
Kodak & 0.0494 & 10.5585 & -12.2729 & 1.6496 & 0.0654 & 6.1489 \\
Exxon & 0.0349 & 5.6240 & -4.3222 & 1.1266 & 0.1079 & 1.1863 \\
Honeywell & 0.0745 & 12.4121 & -6.3918 & 1.6350 & 0.6464 & 4.2264 \\
HP & 0.0926 & 13.2552 & -19.3955 & 2.1933 & 0.0526 & 6.3984 \\
IBM & 0.0092 & 11.0782 & -11.3736 & 1.7086 & 0.0476 & 6.0508 \\
INTL Paper & 0.0252 & 6.7090 & -8.7292 & 1.4437 & 0.0676 & 1.4353 \\
JP Morgan & 0.0428 & 6.6975 & -6.0331 & 1.4796 & 0.2936 & 1.7619 \\
JJ & 0.0729 & 7.5801 & -6.4568 & 1.5008 & 0.0241 & 1.3069 \\
MCD & 0.0647 & 6.3149 & -8.7011 & 1.5088 & 0.0296 & 1.4721 \\
MERCK & 0.0555 & 5.3820 & -6.3911 & 1.5369 & 0.0178 & 0.9606 \\
MSFT & 0.1548 & 9.9091 & -8.1041 & 2.1203 & 0.1389 & 1.2503 \\
MMM & 0.0343 & 4.9461 & -9.0476 & 1.1752 & -0.3528 & 4.0753 \\
PM & 0.0565 & 6.2250 & -26.1523 & 1.6107 & -2.6417 & 43.6380 \\
PG & 0.0578 & 5.5280 & -5.6041 & 1.3212 & 0.1523 & 1.1559 \\
SBC & 0.0271 & 7.2321 & -5.3476 & 1.3374 & -0.0031 & 1.1647 \\
United Tec & 0.0441 & 8.3160 & -6.9054 & 1.4424 & 0.2320 & 2.6466 \\
Walmart & 0.0486 & 7.5913 & -9.8961 & 1.7352 & -0.0047 & 1.8396 \\
Disney & 0.0491 & 11.2655 & -6.6880 & 1.5806 & 0.4532 & 2.6014 \\
Intel & 0.1301 & 9.009 & -14.5082 & 2.3631 & -0.3969 & 2.9882 \\
\hline US 1-month TB & 0.0128 & 0.0218 & 0.0059 & 0.0039 & 0.2609 & -0.9868 \\
S\&P500 & 0.0401 & 3.6642 & -3.7272 & 0.7268 & -0.1664 & 2.3902 \\
\hline Notes: The & 6.969 \\
\hline
\end{tabular}

Notes: The statistics are based on 1618 observations. The sample period is January 1990 through May 1996. 
Table 2: Model estimates

\begin{tabular}{|c|c|c|c|c|c|}
\hline \multirow{2}{*}{ Parameter } & \multicolumn{5}{|c|}{ Number of volatility switching regimes } \\
\hline & 2 & 3 & 4 & 5 & 6 \\
\hline Intercept & 0.035 & 0.0290 & 0.0369 & 0.0393 & 0.0428 \\
\hline$P_{11}$ & 0.987 & 0.2731 & 0.6795 & 0.6923 & 0.7228 \\
\hline$P_{12}$ & 0.013 & 0.7039 & 0.3049 & 0.2867 & 0.2430 \\
\hline$P_{13}$ & & 0.0230 & 0.0100 & 0.0100 & 0.0132 \\
\hline$P_{14}$ & & & 0.0056 & 0.0100 & 0.0100 \\
\hline$P_{15}$ & & & & 0.0010 & 0.0100 \\
\hline$P_{21}$ & 0.029 & 0.3308 & 0.1992 & 0.1598 & 0.0595 \\
\hline$P_{22}$ & 0.971 & 0.6682 & 0.7898 & 0.8192 & 0.9095 \\
\hline$P_{23}$ & & 0.0010 & 0.0100 & 0.0100 & 0.0100 \\
\hline$P_{24}$ & & & 0.0010 & 0.0100 & 0.0100 \\
\hline$P_{25}$ & & & & 0.0010 & 0.0100 \\
\hline$P_{31}$ & & 0.0130 & 0.0100 & 0.0100 & 0.0100 \\
\hline$P_{32}$ & & 0.0100 & 0.0100 & 0.0100 & 0.0100 \\
\hline$P_{33}$ & & 0.9770 & 0.9574 & 0.9604 & 0.9583 \\
\hline$P_{34}$ & & & 0.0226 & 0.0186 & 0.0107 \\
\hline$P_{35}$ & & & & 0.0010 & 0.0100 \\
\hline$P_{41}$ & & & 0.0100 & 0.0100 & 0.0100 \\
\hline$P_{42}$ & & & 0.0100 & 0.0100 & 0.0468 \\
\hline$P_{43}$ & & & 0.0727 & 0.0979 & 0.1089 \\
\hline$P_{44}$ & & & 0.9073 & 0.8811 & 0.8233 \\
\hline$P_{45}$ & & & & 0.0010 & 0.0100 \\
\hline$P_{51}$ & & & & 0.0649 & 0.0258 \\
\hline$P_{52}$ & & & & 0.0704 & 0.1022 \\
\hline$P_{53}$ & & & & 0.0804 & 0.1124 \\
\hline$P_{54}$ & & & & 0.0629 & 0.0471 \\
\hline$P_{55}$ & & & & 0.7214 & 0.7116 \\
\hline$P_{61}$ & & & & & 0.0528 \\
\hline$P_{62}$ & & & & & 0.0569 \\
\hline$P_{63}$ & & & & & 0.0604 \\
\hline$P_{64}$ & & & & & 0.0531 \\
\hline$P_{65}$ & & & & & 0.0475 \\
\hline$\sigma_{1}$ & 0.554 & 0.2526 & 0.3133 & 0.3095 & 0.2804 \\
\hline$\sigma_{2}$ & 1.057 & 0.6805 & 0.6505 & 0.6102 & 0.5481 \\
\hline$\sigma_{3}$ & & 1.0889 & 0.7665 & 0.7575 & 0.7998 \\
\hline$\sigma_{4}$ & & & 1.4220 & 1.4728 & 1.5186 \\
\hline$\sigma_{5}$ & & & & 2.0715 & 2.0325 \\
\hline$\sigma_{6}$ & & & & & 2.5770 \\
\hline MLE & -624.73 & -615.44 & -614.53 & -615.75 & -619.94 \\
\hline AIC & 0.9220 & 0.9157 & 0.9246 & 0.9396 & 0.9619 \\
\hline
\end{tabular}

Note: The estimation period is January 1990 to May 1995 spanning 1366 days. 
Table 3: Beta estimates

\begin{tabular}{|c|c|c|c|c|c|c|}
\hline \multirow{2}{*}{$\begin{array}{l}\begin{array}{l}\text { Model } \\
\text { estimated }\end{array} \\
\text { Security }\end{array}$} & \multicolumn{4}{|c|}{$\begin{aligned} & \text { Three-beta security return generating process } \\
R_{i t}= & \alpha_{i}+\beta_{i L} d_{L t} R_{m t}+\beta_{i N} d_{N t} R_{m t}+\beta_{i H} d_{H t} R_{m t}+\varepsilon_{i t}\end{aligned}$} & \multicolumn{2}{|c|}{$\begin{array}{c}\text { Market model } \\
R_{i t}=\alpha_{i}+\beta_{i} R_{m t}+\varepsilon_{i t}\end{array}$} \\
\hline & $\alpha_{i}$ & $\beta_{i L}$ & $\beta_{i N}$ & $\beta_{i H}$ & $\alpha_{i}$ & $\beta_{i}$ \\
\hline$\overline{\text { Dupont }}$ & 0.0040 & $1.2231^{*}$ & $1.0024^{* * *}$ & $1.1351^{* * *}$ & 0.0049 & $1.0762^{* * *}$ \\
\hline Boeing & 0.0035 & 0.2700 & $0.7455^{* * *}$ & $1.2260^{* * *}$ & -0.0033 & $1.0073^{* * *}$ \\
\hline Caterpillar & 0.0266 & 0.4745 & $1.0371^{* * *}$ & $1.0058^{* * *}$ & 0.0223 & $1.0176^{* * *}$ \\
\hline Alcoa & -0.0237 & $2.5013^{* * *}$ & $0.9824^{* * *}$ & $0.8507^{* * *}$ & -0.0107 & $0.9164^{* * *}$ \\
\hline Amex & -0.0225 & 0.6419 & $1.0618^{* * *}$ & $1.5286^{* * *}$ & -0.0288 & $1.3163^{* * * *}$ \\
\hline $\mathrm{ATT}$ & -0.0135 & -0.1127 & $0.9955^{* * *}$ & $0.9991^{* * *}$ & -0.0223 & $0.9928^{* * *}$ \\
\hline CITIGRP & 0.0318 & $1.9583^{* *}$ & $1.5751^{* * *}$ & $1.2699^{* * *}$ & 0.0368 & $1.4091^{* * *}$ \\
\hline Coca Cola & $0.0561^{*}$ & 0.1088 & $1.1857^{* * *}$ & $1.2553^{* * *}$ & 0.0470 & $1.2194^{* * *}$ \\
\hline Home Depot & $0.0845^{* *}$ & 0.1012 & $1.4981^{* * *}$ & $1.6184^{* * *}$ & $0.0726^{* *}$ & $1.5583^{* * *}$ \\
\hline GE & 0.0110 & 0.7792 & $1.0699^{* * *}$ & $1.1702^{* * *}$ & 0.0080 & $1.1237^{* * *}$ \\
\hline GM & -0.0332 & 1.3086 & $1.3430^{* * *}$ & $1.3173^{* * *}$ & -0.0333 & $1.3288^{* * *}$ \\
\hline Kodak & 0.0129 & $1.3722^{*}$ & $0.7590^{* * *}$ & $1.0527^{* * *}$ & 0.0159 & $0.9228^{* * *}$ \\
\hline Exxon & 0.0033 & $1.0753^{* *}$ & $0.6782^{* * *}$ & $0.6346^{* * *}$ & 0.0067 & $0.6559^{* * *}$ \\
\hline Honeywell & 0.0365 & 0.7479 & $0.9547^{* * *}$ & $0.8420^{* * *}$ & 0.0356 & $0.8920^{* * *}$ \\
\hline $\mathrm{HP}$ & 0.0276 & $2.6639^{* * *}$ & $1.3732^{* * *}$ & $1.3862^{* * *}$ & 0.0379 & $1.3857^{* * *}$ \\
\hline IBM & -0.0280 & 1.2980 & $0.9270^{* * *}$ & $0.8945^{* * *}$ & -0.0248 & $0.9107^{* * *}$ \\
\hline INTL Paper & -0.0106 & $1.7384^{* *}$ & $0.9197^{* * *}$ & $1.0001^{* * *}$ & -0.0045 & $0.9673^{* * *}$ \\
\hline JP Morgan & 0.0050 & 0.6117 & $1.1152^{* * *}$ & $1.0678^{* * *}$ & 0.0013 & $1.0871^{* * *}$ \\
\hline JJ & 0.0212 & $1.4366^{* *}$ & $1.2014^{* * *}$ & $1.0723^{* * *}$ & 0.0239 & $1.1315^{* * *}$ \\
\hline MCD & 0.0260 & 0.7193 & $1.1179^{* * *}$ & $1.0414^{* * *}$ & 0.0232 & $1.0742^{* * *}$ \\
\hline MERCK & 0.0110 & 0.8539 & $1.0770^{* * *}$ & $1.1274^{* * *}$ & 0.0089 & $1.1038^{* * *}$ \\
\hline MSFT & $0.1210^{* *}$ & 1.5361 & $1.3502^{* * *}$ & $1.3856^{* * *}$ & $0.1223^{*}$ & $1.3704^{* * *}$ \\
\hline MMM & 0.0046 & 0.6940 & $0.8284^{* * *}$ & $0.8572^{* * *}$ & 0.0033 & $0.8437^{* * *}$ \\
\hline PM & 0.0041 & $1.5897^{* *}$ & $1.0260^{* * *}$ & $1.1366^{* * *}$ & 0.0079 & $1.0891^{* * *}$ \\
\hline PG & 0.0189 & $1.0638^{*}$ & $1.1270^{* * *}$ & $1.0416^{* * *}$ & 0.0189 & $1.0798^{* * *}$ \\
\hline SBC & -0.0092 & $1.5993^{* *}$ & $1.0031^{* * *}$ & $0.8887^{* * *}$ & -0.0037 & $0.9428^{* * *}$ \\
\hline United Tec & -0.0033 & 1.0436 & $0.8736^{* * *}$ & $0.8938^{* * *}$ & -0.0020 & $0.8854^{* * *}$ \\
\hline Walmart & 0.0121 & $1.6843^{* *}$ & $1.3177^{* * *}$ & $1.5291^{* * *}$ & 0.0137 & $1.4353^{* * *}$ \\
\hline Disney & 0.0223 & 0.4429 & $1.0862^{* * *}$ & $1.1363^{* * *}$ & 0.0169 & $1.1110^{* * *}$ \\
\hline Intel & $0.1004^{*}$ & 0.9597 & $1.6641^{* * *}$ & $1.3186^{* * *}$ & $0.0970^{* *}$ & $1.4715^{* * *}$ \\
\hline
\end{tabular}

Notes: ${ }^{* * *}$ indicates significant at the 1 percent level, ${ }^{* *}$ at the 5 percent level and ${ }^{*}$ at the 10 percent level. $d_{k t}=1$, if market is in volatility regime $k$ and $d_{k t}=0$ otherwise where, $k=L, N, H$. Of the 1366 sampled days the market is in the low, neutral and high volatility regimes in 311 (22.77\%), 714 (52.27\%) and 341 (24.96) days respectively. 
Table 4: p-values from F-tests

\begin{tabular}{|c|c|c|c|c|}
\hline Security & $H_{0}: \beta_{i L}=\beta_{i N}$ & $H_{0}: \beta_{i L}=\beta_{i H}$ & $H_{0}: \beta_{i N}=\beta_{i H}$ & $H_{0}: \beta_{i L}=\beta_{i N}=\beta_{i H}$ \\
\hline Dupont & 0.7377 & 0.8937 & 0.1344 & 0.3178 \\
\hline Boeing & 0.5386 & 0.2161 & $0.0000^{* * *}$ & $0.0000^{* * *}$ \\
\hline Caterpillar & 0.5041 & 0.5278 & 0.7821 & 0.7794 \\
\hline Alcoa & $0.0580^{*}$ & $0.0393^{* *}$ & 0.2217 & $0.0655^{*}$ \\
\hline Amex & 0.6566 & 0.3474 & $0.0002^{* * *}$ & 0.0009 \\
\hline ATT & $0.0643^{*}$ & $0.0632^{*}$ & 0.9643 & 0.1775 \\
\hline CITIGRP & 0.6897 & 0.4729 & $0.0182^{* *}$ & $0.0521^{*}$ \\
\hline Coca Cola & $0.0743^{*}$ & $0.0572^{*}$ & 0.3908 & 0.1244 \\
\hline Home Depot & $0.0985^{*}$ & $0.0725^{*}$ & 0.2898 & 0.1270 \\
\hline GE & 0.5645 & 0.4381 & 0.1397 & 0.2654 \\
\hline GM & 0.9699 & 0.9924 & 0.8342 & 0.9781 \\
\hline Kodak & 0.4584 & 0.6990 & $0.0084^{* * *}$ & $0.0265^{* *}$ \\
\hline Exxon & 0.4652 & 0.4173 & 0.5510 & 0.6194 \\
\hline Honeywell & 0.8027 & 0.9094 & 0.3117 & 0.5901 \\
\hline HP & 0.2095 & 0.2138 & 0.9246 & 0.4549 \\
\hline IBM & 0.6532 & 0.6248 & 0.7696 & 0.8570 \\
\hline INTL Paper & 0.2291 & 0.2777 & 0.3798 & 0.3545 \\
\hline JP Morgan & 0.4752 & 0.5174 & 0.6174 & 0.7008 \\
\hline $\mathrm{JJ}$ & 0.7363 & 0.6017 & 0.1698 & 0.3538 \\
\hline MCD & 0.5702 & 0.6462 & 0.4173 & 0.6320 \\
\hline MERCK & 0.7575 & 0.7049 & 0.6043 & 0.8230 \\
\hline MSFT & 0.8519 & 0.8797 & 0.7918 & 0.9523 \\
\hline MMM & 0.7967 & 0.7543 & 0.6817 & 0.8818 \\
\hline PM & 0.4678 & 0.5592 & 0.2895 & 0.4619 \\
\hline PG & 0.9138 & 0.9696 & 0.2770 & 0.5535 \\
\hline SBC & 0.3407 & 0.2557 & 0.1739 & 0.2274 \\
\hline United Tec & 0.8143 & 0.8358 & 0.8358 & 0.9553 \\
\hline Walmart & 0.6188 & 0.8330 & $0.0331^{* *}$ & $0.0973^{*}$ \\
\hline Disney & 0.3990 & 0.3629 & 0.6254 & 0.6017 \\
\hline Intel & 0.5312 & 0.7495 & $0.0225^{* *}$ & $0.0666^{*}$ \\
\hline
\end{tabular}

Notes: ${ }^{* * *}$ indicates significant at the 1 percent level, ${ }^{* *}$ at the 5 percent level and ${ }^{*}$ at the 10 percent level. 
Table 5: Risk premium estimates in the unconditional three-beta asset pricing model

\begin{tabular}{lcccc}
\hline & $\lambda_{0}$ & $\lambda_{L}$ & $\lambda_{N}$ & $\lambda_{H}$ \\
\hline Mean & 0.0766 & 0.0003 & 0.0039 & 0.0196 \\
Standard Deviation & 0.1196 & 0.0306 & 0.1137 & 0.1043 \\
$t$-value & 0.6406 & 0.0100 & 0.0343 & 0.1877 \\
\hline
\end{tabular}

Notes: The $\lambda$ is estimated over 252 days

Table 6: Risk premium estimates in the conditional three-beta asset pricing model

\begin{tabular}{lrrrrrrrr}
\hline & \multicolumn{3}{c}{ Up market (n=110 days) } & \multicolumn{5}{c}{ Down market (n=142 days) } \\
\cline { 2 - 9 } & \multicolumn{1}{c}{$\lambda_{0}^{U}$} & \multicolumn{1}{c}{$\lambda_{L}^{U}$} & \multicolumn{1}{c}{$\lambda_{N}^{U}$} & $\lambda_{H}^{U}$ & \multicolumn{1}{c}{$\lambda_{0}^{D}$} & \multicolumn{1}{c}{$\lambda_{L}^{D}$} & \multicolumn{1}{c}{$\lambda_{N}^{D}$} & \multicolumn{1}{c}{$\lambda_{H}^{D}$} \\
\hline Mean & -0.0527 & 0.0800 & 0.2828 & 0.2153 & 0.2436 & -0.1026 & -0.3562 & -0.2331 \\
Std dev & 0.1592 & 0.0408 & 0.1413 & 0.1456 & 0.1808 & 0.0444 & 0.1811 & 0.1447 \\
$t$-value & -0.3312 & $1.9608^{* *}$ & $2.0013^{* *}$ & 1.4786 & 1.3470 & $-2.3101^{* *}$ & $-1.9670^{* *}$ & -1.6113 \\
\hline
\end{tabular}

Notes: ${ }^{* *}$ indicates significant at the 5 percent level. 